\title{
The Significance of Silent Moments in Creating Words for the Not-Yet-Spoken Experiences in Threat of Divorce
}

\author{
Saara Itävuori*, Essi Korvela*, Anu Karvonen, Markku Penttonen, Jukka Kaartinen, \\ Virpi-Liisa Kykyri, Jaakko Seikkula \\ Department of Psychology, University of Jyvaskyla, Jyvaskyla, Finland \\ Email: saara.h.itavuori@student.jyu.fi, essi.korvela@luukku.com
}

Received 23 June 2015; accepted 21 August 2015; published 25 August 2015

Copyright (C) 2015 by authors and Scientific Research Publishing Inc.

This work is licensed under the Creative Commons Attribution International License (CC BY).

http://creativecommons.org/licenses/by/4.0/

cC) (i) Open Access

\begin{abstract}
In the context of couple therapy involving the threat of divorce, the study examined the significance of silent moments for arriving at words for the not-yet-spoken experiences. It also examined whether interactional and embodied synchrony occurred during such silent moments. A mixed method analysis was conducted, focusing on the therapeutic dialogue, psychophysiological data (the Autonomic Nervous System, ANS), and the participants' thoughts and feelings during individual Stimulated Recall interviews. Two episodes containing several silent moments were analyzed. The analysis indicated that during the silent moments the participants continued the therapeutic conversations through their entire bodies. Moreover, the conversation on fundamental issues such as the permanence of the relationship and the possible separation of family members continued after the silent moments. Synchrony was observed between the participants during the silent moments, particularly in the prosody of the speech and in the ANS reactions. In the ANS data, breathing emerged as the most prominent and interesting measure, providing new information on bodily reactions during silent moments. We suggest that silent moments played a key role in arriving at words for experiences that had not been spoken of; they promoted the rhythm of the conversation, and allowed the conversation to move forward, giving the participants a chance to react and to think. These are aspects, which can be seen as necessary for the discussion of fundamental issues.
\end{abstract}

\section{Keywords}

Silent Moments, Prosody, Therapeutic Dialogues, Autonomic Nervous System, Synchrony

\footnotetext{
*The two authors had the main responsibility of writing this paper and the rest of the authors have contributed to the design of the project, analysis of the results and formulation of the paper.

How to cite this paper: Itävuori, S., Korvela, E., Karvonen, A., Penttonen, M., Kaartinen, J., Kykyri, V.-L., \& Seikkula, J. (2015). The Significance of Silent Moments in Creating Words for the Not-Yet-Spoken Experiences in Threat of Divorce. Psychology, 6, 1360-1372. http://dx.doi.org/10.4236/psych.2015.611133
} 


\section{Introduction}

Within the human sciences, an "affective turn" (Cromby, 2012) or a "corporeal turn” (Sheets-Johnstone, 2010) is taking place. This is bound up with an increasing interest in corporeal issues and in embodiment within interactions. The basic idea of embodiment is that all human psychological processes are influenced by the brain and by the physiology of the body. A parallel development is taking place in psychotherapy research, especially in studies on the interactions between clients and therapists at the bodily level during psychotherapy. Embodied approaches can be useful in addressing important topics, including the significance of non-verbal synchrony for the therapeutic alliance and for the outcome of the therapy (Ramseyer \& Tschacher, 2011). The present study focused on the silent moments within one couple therapy session, and it used the embodiment approach as a means towards an understanding of therapeutic interactions during which clients are searching for words for painful or otherwise complicated experiences which have not yet been voiced. Seikkula, Karvonen, Kykyri, Kaartinen and Penttonen (2015) have found evidence to suggest that the embodied experiences that originate in relationships are also stored within the memory of the body, and that these memories are activated in relational situations. Studying silences within and between turns can offer information on these experiences. For example, speakers may look for words to describe their own experiences, and in the process of forming a narrative from the experiences there may be hesitations, silent moments, and changes in prosody, possibly because no words exist for the experiences at this point. In this kind of moment, the speaker is often dealing with the kind of affective arousal that happens before arriving at a precise formulation of the emotions concerned. In therapy dialogue, silent moments and pauses between words can form arenas in which these non-conscious experiences can be lived and expressed in interaction. Once these embodied memories are formulated into outer or inner words, they are no longer unconscious entities. According to Bakhtin (1984), a human participates in dialogue throughout his or her life, using the entire body in all interactions. In the conceptions of Bakhtin, the human mind is polyphonic, meaning that our mutual dialogue is influenced by the current interaction with our partners, our previous relationships, our life experiences, and our traumas. In dialogical practice the therapists primarily synchronize their language with the client by using the client's own words (Seikkula et al., 2015). By this means the participants attune to each other within the outer dialogue. At the same time, the inner dialogue plays an important role because it influences what is said, and how the issue in question is uttered (Seikkula \& Arnkil, 2007). Moving beyond this, the embodied component can be identified as a significant part of the dialogue in therapeutic environment, taking into account the fact that no more than 30 to 35 percent of social interaction takes place through words (Birdwhistell, 1952).

A newborn baby will typically synchronize body movements, facial expressions, and gestures with her caregiver (Bràten \& Trevarthen, 2007; Trevarthen, 2001). The foundation of this phenomenon lies in intersubjectivity — our human tendency to attune with each other, so that we share mutual understanding in an interaction. A baby learns social interaction via intersubjectivity, first with her caregiver and soon after with an entire "village" of relationships (e.g. Hrdy, 2009). This is why it is valid to take into account the multi-actor aspect in therapeutic situations; participants tend to synchronize with each other through their words and their whole bodies.

Moments of synchrony happen "here and now". They usually last a couple of seconds and are highly context sensitive (Altenstein, Krieger, \& Grosse Holtforth, 2013; Stern, 2004). Synchrony can often be dyadic or triadic, and usually therapists will synchronize more precisely with one of the clients, thus forming various therapistclient pairs within couple therapy (Seikkula et al., 2015). Weiste and Peräkylä (2014) found that the similarity of the speech pitch between therapists and clients was significant for the client's experience of the therapist's empathy. Speech synchrony between the therapist and the client is also related to forming a good therapeutic alliance, and further, to the client's experience of being heard (Seikkula \& Arnkil, 2007).

In psychotherapy research, the intersubjectivity approach has led to an increased interest in the embodied synchrony of human psychological functioning (Cromby, 2012). Despite this, there has been only limited research on embodied synchrony. Ramseyer and Tschacher (2011) observed that body movements between therapists and clients can increase cooperation in the relationship, and can contribute to a better therapeutic outcome. Some progress in the field has been made through observations of autonomic nervous system (ANS) reactions. In line with this, Levenson and Ruef (1997) noticed that synchrony in physiological reactions between the client and the therapist is related to emotional synchrony. There has also been increasing interest in electrodermal activity (EDA). Several studies have shown that concordance in EDA activity is related to perceived empathy between the participants (Marci, Ham, Moran, \& Orr, 2007; Messina et al., 2013; Slovák, Tennent, 
Reeves, \& Fitzpatrick, 2014); also that emotional distance is related to a weak concordance between EDA and the perceived empathy between the participants (Marci \& Orr, 2006).

The present study emerged from a multi-method study of one psychotherapy case by Kykyri, Karvonen, Wahlström, Penttonen, Kaartinen \& Seikkula (under review, 2015) who explored the role of "soft prosody” in therapeutic change, focusing on one episode when a client was weeping. According to their findings, the studied episode was a moment of active therapeutic work, which led to a change in the interaction. The change manifested shared understanding and embodied attunement, and within it, silences and soft prosody appeared to play a supporting role in conveying affiliation, in achieving embodied attunement, and in offering therapeutic formulations.

In therapy, silence is usually seen as an accepted, and even expected part of the conversation (Levitt, 2001). For therapists it is an important tool that makes it possible to gain a better understanding of the client's conflicts and defenses, resistances, adaptive functioning, and interpersonal style, with an insight also into the therapeutic relationship (Lane, Koetting, \& Bishop, 2002). Thus, silence can indicate that a client's emotions are awakening (Gendlin, 1996) and it may also function as a channel for the therapist to demonstrate empathy with the client (Hill, Thompson, \& Ladany, 2003). According to both Wepfer (1996) and Cook (1964), silence may be associated with a client's experience of insight, and with therapeutic success; hence, it can be a productive element in the therapy. Silence has also been seen as a turning point in the narrative report (Gee, 1986). Sabbadini (1991) suggested that silence forms a space for words that cannot be spoken, and hence that therapists should pay attention to silences, so that they can notice when and why some issues are difficult for the client.

Prosody is related to the musical properties of speech expression, such as rhythm, melody, flow, intonation, and pitch (Couper-Kuhlen \& Selting, 1996; Reed, 2010). Prosody is particularly important in dealing with conflicts; thus, Lapides (2011) noticed that clients pay attention mainly to how something is said (the prosody of the speech) rather than to what is actually said (see also Quillman, 2012). MacGregor, Corley and Donaldson (2010) found that the listener hears and takes better into account things that are said with "soft" prosody, i.e. lowering speech's rhythm or pitch. It has also been noted that soft prosody usually appears in close association with silences. What might be termed a lesser density of words may be used in the course of soft prosody, meaning that there are silences within conversational turns. These might be associated with the difficulty of finding words (Kircher, Brammer, Levelt, Bartels, \& McGuire, 2004), or with the sensitivity of the topic. Therapists, too, can change their prosody, for example by lowering their pitch and softening their speech (Weiste \& Peräkylä, 2014), and in this way show empathy.

ANS activity is connected to arousal and to a variety of emotions, and is thus capable of providing additional quantitative information on emotional experiences (Levenson, 2014; Kreibig, 2010). Assuming that the body’s inner state manifests a constant attempt to adapt to the surrounding world, researchers have reason to analyze ANS reactions within a therapy setting where multiple persons are present. Here it is worth noting that research on emotions has tended to be conducted using stimuli that are irrelevant to the participant's personal history. By contrast, during actual therapy, the context is relevant for all the participants and can thus elicit real emotions. These may be observed, for example, via sympathetic nervous system synchrony between the participants, which appears to be related to perceived empathy, and further, to positive social-emotional responses in behavior (Marci \& Orr, 2006; Marci et al., 2007; Messina et al., 2013; Slovák et al., 2014).

In the present study, we examined silent moments by looking at the participants' electrodermal activity (EDA), breathing, and heart rate (HR). We considered that breathing would be an interesting measure, given that the changes in the rhythm of breathing that occur during speech do not occur during silent moments. Normally, when a person is not speaking, the breathing rhythm is steady, making it of interest to observe any exceptions that may occur during silent moments. We chose to study EDA on the grounds that during silences speech does not have a strong effect on EDA; thus, if silences elicit a wide range of emotions in participants, it may be possible to observe these in the EDA measurements. HR was chosen as a measure in accordance with our view that it could reflect immediate reactions within silent moments, which might last only few seconds.

The ANS consists of the sympathetic nervous system (SNS) and the parasympathetic nervous system (PNS). SNS prepares the body for action (“fight-or-flight”), and it is activated when emotions are experienced. EDA measurements can thus give information on SNS activity via changes in the arousal level of the participant. The PNS is active in states of resting and recovery ("rest-and-digest"), and parasympathetic control of the heart rate is dominant during non-strenuous moments. According to current knowledge, SNS and PNS are not in fact antagonists, and can be active at the same time. Concerning breathing, according to Feleky's (1916) early studies, 
surprise can be manifested as holding one's breath, while anxiety has been found to be related to fast and shallow breathing (Blechert et al., 2006).

It should be borne in mind that the ANS reactions are not restricted to manifestations of aroused emotions; they are also responsible for the basic functions of the body. It is also natural for people to have orienting responses to new information, irrespective of any specific emotional responses. In this study, the goal was not to identify specific different emotions from the ANS reactions - an aim that Levenson (2014), too, has seen as questionable - but rather to use the ANS data to help us gain a better understanding of the multi-actor therapy situation in terms of its embodied dialogue.

Our specific interest was to look at how, during couple therapy dialogues for a threatening divorce situation, the participants used silent moments as a context to bring to the fore new words and meanings for difficult experiences. To do this, silent moments were approached both as integral elements of the therapy interaction and via an embodied perspective, examining how, during these silences, the participants were related to each other at a bodily level. In pursuing this aim, we combined observations from the therapeutic dialogue, participants' psychophysiological data (ANS), and the participants' thoughts and feelings as they were reported during individual interviews after the session. In addition, the study aimed to examine whether synchrony could be found between participants at a dialogical levels during the silent moments. As far as we know, no previous research has been conducted in this manner. In seeking to obtain answers to these questions we selected two episodes containing several silent moments, and applied a mixed method analysis.

\section{Data and Methods}

This study was conducted within the "Relational mind in events of change in multi-actor therapeutic dialogues" research project. The project forms part of the Finnish Academy's Program "Human mind" and conducted at the University of Jyväskylä, Department of Psychology in collaboration with five European Universities. Data for the project are gathered at the Jyväskylä University Psychotherapy Training and Research Centre. Each therapy process includes two measurement sessions, which include ANS recordings for each participant, and Stimulated Recall (SR) interviews. The Ethical Board of the University of Jyväskylä approved the methods used in the study. All the participants gave their informed written consent.

\subsection{The Case and Design}

We studied one couple and their two therapists. The couple contacted Jyväskylä University Psychotherapy Training and Research Centre to obtain treatment for intimate partner violence and for communication problems. The male client had been diagnosed with depression, for which he had been given medication. The female client had given birth a few months previously. The therapists were experienced male therapists. The therapy was non-manualized, but it always contained reflective conversations between the therapists, and it combined dialogical, narrative, and reflective orientations. To protect privacy, all authentication information has been changed here. For the purposes of this article, we have named the clients Heli (the female client) and Lasse (the male client), while the therapists are referred to as T1 and T2. The therapy sessions were video-recorded with a split screen between the therapists and the clients, using two cameras in such a way as to cover the whole setting. Precise facial images of the participants were captured with one camera for each participant, enabling the participant's facial expressions to be seen in detail.

In the second and sixth sessions and in the Stimulated Recall (SR) interviews, all the participants wore equipment to measure ANS responses (HR, breathing, and EDA). HR was measured using the First beat Bodyguard recording method (First beat Technologies) (e.g. Kinnunen et al., 2006). This equipment was attached to two sites on the skin of the chest, one day before the therapy session. It was removed only for showering or swimming. HR measuring ended after the SR interviews. EDA, as measured through skin conductance (SC), and also breathing, were recorded with a Brainamp ExG16 amplifier and a data acquisition system (Brain Products) amplifier at $1000 \mathrm{~Hz}$ sampling frequency, using the Brain Vision Recorder program. SC was measured from the participants' non-dominant hand, with disposable $\mathrm{Ag} / \mathrm{AgCl}$ electrodes placed on the palmar surfaces, close to the index and little finger. Breathing was measured by means of a flexible fabric breathing belt, which was attached around the lower chest. Continuous numerical values indicated the stretching of the belt during respiratory cycles. This provided data showing the variations in inspiratory and expiratory movement, the depth of breathing, and the breathing rate. In addition to the above indicators, finger pulse volume (FPV, Brain Products) 
and vocal muscle movements were measured using a throat microphone during the SR interviews. Most of the ANS data were analyzed using a custom-made data review program.

After the measurement session, everyone participated in the SR interviews (Kagan, Krathwohl, \& Miller, 1963), one person at a time, within one day of the therapy session. The researcher showed four video extracts from the session and asked the participants about the thoughts, feelings, and body sensations they had experienced during these moments. The interview was recorded with two cameras, one providing a general view of the participant and the researcher, and the other a detailed view of the face of the participant. The interviews lasted 30 - 40 minutes.

\subsection{Analysis}

The mixed method analysis started by looking at all ten of the couple's video-recorded therapy sessions, to gain an understanding of this particular case and to locate silences in the sessions. First of all, silent moments were identified and located. Here it should be noted that in fact we selected two types of events that we have labelled "silent moments," according to the following criteria:

1) silences (no speech at all) with a duration of more than three seconds;

2) sequences that manifested a change towards soft prosody, for example when participants lowered their speech volume, or the rhythm or intonation became slower. These were noted in one-second intervals.

The context of the selected silent moments was then defined according to the theme of the conversation, for example when talking about possible divorce.

The sixth therapy session was the one we chose for detailed consideration. The selection of this session was based on the availability of all three sources of data (the therapeutic dialogue, the ANS measurements, and the SR interviews), in addition to the number of silences. Within this session, 39 moments met the criteria for silent moments, the durations of which varied from a few seconds to several tens of seconds. Most of the silent moments (about 85\%) occurred when: 1) the conversation topic was the possible divorce, 2) the couple talked about conflicts or disagreements in their opinions, or 3) the couple were reflecting on their own thoughts or emotions. Analysis further focused on moments which occurred during conversations about the possible divorce, in which a combination of all three data sources was available. Two particular episodes were selected (see Figure 1 below), as follows:

1) Episode 1 at session time 02:50-05:36, which contained five silent moments. This episode was also selected for the SR interview. The criteria for the selection were Heli's emotional expressions, Heli's and Lasse's EDA responses, and the theme of possible divorce.

2) Episode 2 at session time 43:12-45:10, which contained four silent moments. This episode was also selected for the SR interview. The criteria for the selection were Lasse's visible emotional response, Lasse's and T2's EDA responses, and the theme of where the children should live.

The analysis of the social interaction during the selected episodes focused on both verbal and non-verbal elements of the interaction within the silent moments. The analysis was informed by ideas from discursive psychology (e.g. Potter \& Edwards, 2001), and further, by means of analyzing prosody (Couper-Kuhlen \& Selting, 1996; Barth-Weingarten, Reber, \& Selting, 2010) and emotions (Peräkylä \& Sorjonen, 2012) within interactions. Specifically, we focused on 1) changes in voice quality, including the pitch, timbre, and color of the voice (e.g. strong and firm, or timid and tremulous, or soft and gentle), as well as incidences of "broken voice," "hoarse

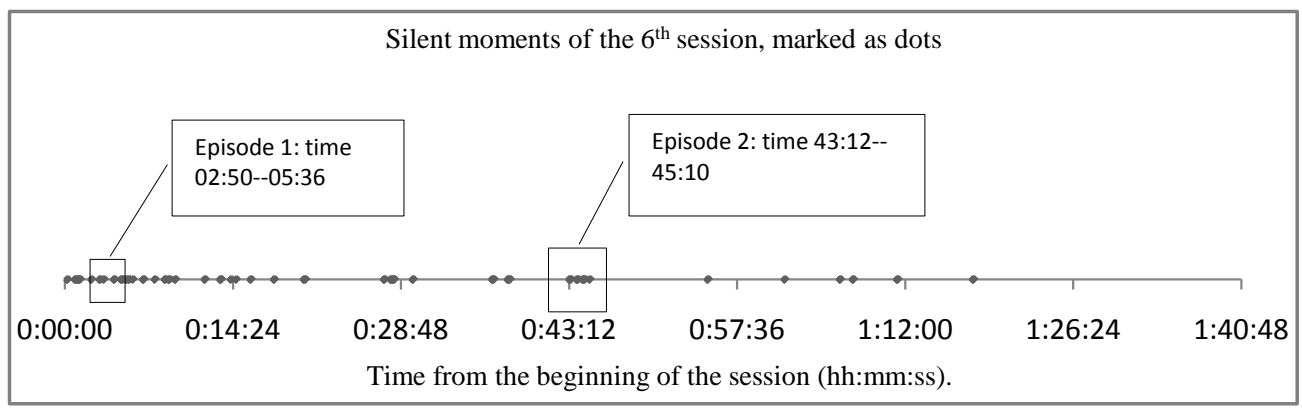

Figure 1. Silent moments from the $6^{\text {th }}$ session. The squares indicate episodes 1 and 2. 
throat,” and stammering; 2) clearly visible emotional expressions (e.g. becoming moved, crying, smiling, laughing), in addition to clearly visible micro-expressions (e.g. biting a lip); 3) gazes and other ways of being in touch with the other participants. All in all, the analysis of the interviews focused mainly on the verbal content, considering also clearly observable changes in the pitch of the voice and emotional expressions.

The observations from the separate analyses were then integrated, with a view to identifying the significance of the silent moments in the interaction. The transcriptions from the session and from the interviews were utilized at various stages of the analysis. The selected episodes were translated into English after the analysis. The transcription symbols are presented in Appendix 1.

\section{Results}

The results from two episodes, both of which contained several silent moments, are presented in this section. We first describe the therapy conversation, giving some examples as verbatim transcriptions. Thereafter, we present the ANS results, and finally observations from the SR interviews. The nine silent moments under study are numbered in their order of occurrence, from silent moment 1 to silent moment 9 . The first episode contained silent moments 1 - 5, and the second episode moments 6 - 9 .

\subsection{Episode 1: The Issue of the Possible Divorce}

Episode 1 (at session time 02:50-05:36) contained five silent moments. During this episode, T2 and Heli had a conversation with each other, while T1 and Lasse were listeners. Both therapists were very attentive during this episode, as shown by their intensive gaze. Lasse was passive in the interaction, and he kept his face averted during the episode, except when Heli showed distress; at these points Lasse looked at her. Heli's prosody varied considerably during Episode 1: it was tough and tight between the silent moments, but her voice became sad and emotional during the silent moments. This "up-and-down" prosodic phenomenon could be viewed as manifesting violently swinging emotions for Heli. Note that the couple had one of their children with them during the session.

Before silent moment 1, Heli had started to describe her feelings and thoughts concerning the relationship. During silent moment 1 (lines 1 - 7, below), after a few seconds of silence (in line 4) Heli used a euphemism and soft prosody, when she started to speak about the possible divorce for the first time. T2 answered with prosodic continuity. This can be seen as a significant moment. Silent moment 1 (lines 1 - 7):

1) Heli: like so it's (.) like it very strongly comes to mind that

2) $T 2: \mathrm{mmm}$

3) Heli: that how like so

4) (3)

5) Heli: what kind of family team we should go ahead with

6) T2: $m m-m h$

7) Heli: if not, then...

After this moment, T2 asked with normal prosody whether Heli meant that they were going to divorce. Heli calmly answered "yes" and after this, silent moment 2 occurred (not shown in the extract). T2 received Heli's response with soft prosody, to which Heli answered with prosodic continuity. The silence occurred between their utterances. After this, Heli started to describe the situation at home with a louder and stronger voice, sounding angry: she thought that Lasse had stopped trying, and she felt anger towards him. Heli's voice turned towards soft prosody when she justified her thoughts, indicating the lack of shared time together. This occurred during silent moment 3 (not shown in the extract). During this moment Heli was biting her lip, which could be seen as an attempt to control the emotional expression. After this, Heli continued the description of her feelings of anger with a louder and stronger voice, before silent moment 4 . When she explained her reasons to be angry, her voice was weak, indicating her emotion during silent moment 4 (lines 8 - 13, below):

8) Heli: I have thought that am I just so (1) completely sick of the situation

9) T2: yeah

10) Heli: or is it (.) just my way to (.) like ((Heli shows signs of tearfulness, Lasse looks at Heli))

11) (1) somehow (1) process (.) the possible divorce (.) like there comes then (2) anger that

12) (.) it would be easier to (.) handle the issue (.) even though (1) I don't know ((Heli

13) is tearful, Lasse looks at Heli)) 
Before silent moment 5, T2 asked if the feeling of anger was a new situation. Heli agreed and said determinedly that she felt anger all the time now. During silent moment 5 (not shown in the extract) she showed emotions for several tens of seconds, as could be heard also from her soft and emotional prosody.

After Episode 1, the discussion moved on to daily conflicts between the couple. They did not mention the possible divorce after Episode 1. Heli still showed emotions, but her voice became more powerful as well as bitter. Lasse and T1 joined the conversation more actively. Later, the therapists had a reflective conversation in which they discussed the couple's "battle fatigue” and the possibility for a new start.

\subsection{Autonomic Nervous System Reactions during Silent Moments 1 - 5}

Electrodermal activity during silent moments 1 - 5: Heli had high EDA, and thus strong SNS activity, during the silent moments of the episode. She also had her third highest EDA peak for the whole session within silent moment 2. The findings here suggest that these moments could have been relevant to Heli. T2 was actively involved in the conversation with Heli, and his SNS showed activation. Lasse and T1 also showed a slight rise in EDA during the silent moments, even though they were in the role of the listener. Congruent EDA responses between all the participants appeared during the silent moments in Episode 1; however, they were mostly between T1-Lasse and T2-Heli.

Breathing during silent moments 1 - 5: All the silent moments appeared in the course of Heli's speech, with her breathing rhythm being correspondingly irregular and variable. Nevertheless, her breathing changed to long inspiratory and short expiratory movements during the silent moments. Lasse held his breath for approximately five seconds during the silent moments, as if frozen within the moments; otherwise his breathing rhythm was regular. The therapists showed a reduction in the depth of their breathing, with their breathing becoming shallower during the silent moments. The holding of breath and the shallow breaths indicate that these moments were relevant to the participants, especially to Lasse. One example of the breathing can be seen in Figure 2, which also depicts the observations mentioned above.

Heart rate during Episode 1: Heli's HR responses were at their highest during this episode, and her HR level was clearly higher than that of the others. Her HR decreased after the episode, but remained at a higher level than that of the other participants during the whole session. Lasse's and T1's HR were at the same level during the episode, and remained at a congruent level throughout the session. T2 had the lowest HR during the episode and also throughout the session. All the participants' HR responses were higher at the beginning of Episode 1 than at the end of it. Congruent responses appeared most often between T1-Lasse, and T2-Heli.

\subsection{Episode 1 Stimulated Recall Interviews}

Heli commented that she had felt tired, sad, and bitter at the start of the episode, but that these feelings had

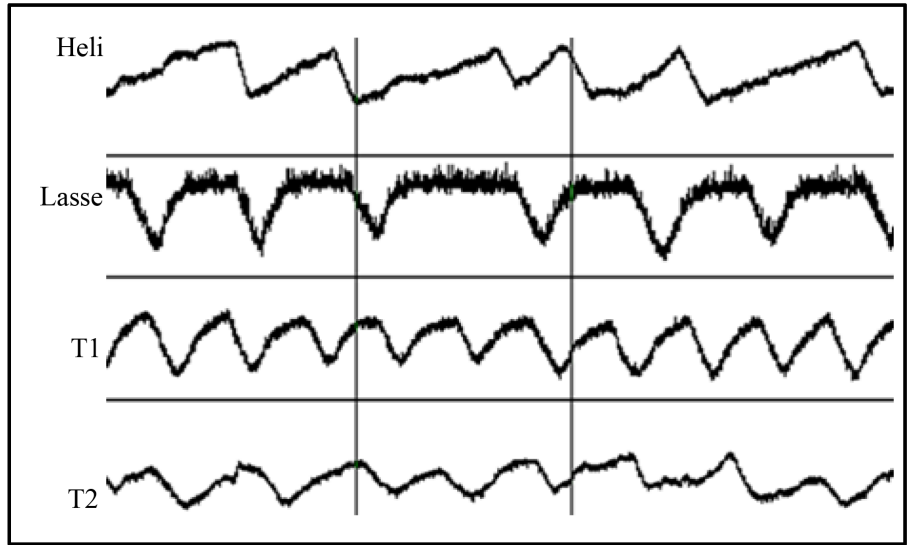

Figure 2. Breathing during silent moment 1 . The length of the silent moment is 9 seconds. In this and the following figure, vertical lines mark the beginning and the end of the silent moment. Individual recordings are each on a separate line; thus the scale of the recording in $\mu \mathrm{S}$ is not shown. 
changed to sorrow when she expressed her feelings aloud. Heli hoped that Lasse had really heard her for the very first time, and this idea was developed in the SR interview. In his interview, Lasse commented that he had noticed Heli's feelings of sadness and contradictory opinions. He had consciously decided to stay quiet because he wanted to explore his own thoughts.

T1 reported that he was both surprised and sad at how the couple's situation had changed. He had become interested when Heli explained her feelings of anger. T1 reported that he had had a relaxed feeling in his body during the episode. He thought that Heli and T2 had had a good conversational rhythm which he did not want to interrupt. T2 also reported that he was surprised at the couple's situation because he thought that they had had a good conversation during the previous therapy session. T2 said that he felt the atmosphere had become more intense during the episode, with the peak occurring when Heli began to speak about the possible divorce. T2 explained that he felt as though he was "gasping for breath" as he listened to Heli's speech. He said that he had winced when Heli mentioned her feelings of anger, and he believed that this wince "could somehow appear as nerve activity".

\subsection{Episode 2: The Issue of where the Children Should Live}

Episode 2 occurred in the middle of the therapy session, at session time 43:12-45:10. Within a period of two minutes four silent moments occurred. Before Episode 2, the session's atmosphere had been lighter, with the conversation no longer directly related to the possible divorce. The clients began to make contact with each other, and they smiled while they were speaking just before the start of Episode 2. At the beginning of Episode 2, all the participants were warmly discussing about Heli's and Lasse's children, but after that the atmosphere rapidly changed, moving to sad and soft prosody. Lasse had one of the children on his lap during this conversation.

During silent moment 6 (not shown in the extract), Heli paid attention to the child and spoke gently to her; then she laughed, and a silence occurred. Right after silent moment 6, T1 changed the topic of the conversation again, returning to the possible divorce by asking a question about life arrangements in the event of divorce. The question surprised the participants, but Heli calmly answered that the children would live with her. This can be seen as meaningful moment, and it was after this that silent moment 7 (lines 14 - 18, below) was manifested in her speech. Heli continued speaking, but her words came one by one, with silences between the words (lines 14 and 17). Lasse started to pet the child on his lap during this moment (in line 17), as if he was answering the same question. Heli stopped her speech for a very short time, apparently taking note of what Lasse was doing, but immediately after the silent moment she continued the speech (lines 20 - 24) with a louder voice, sounding angry. Silent moment 7 is presented below (comprising lines 14 - 18):

14) Heli: -and

15) (3)

16) and and

17) (7) ((Lasse starts to pet the child on his lap))

18) so that (.) ((Heli and Lasse glance at each other))

19) ((Silent moment 7 ends, Heli's voice starts to rise))

20) Heli: $\uparrow$ Sometime Lasse said that well two children to him and two children to me I said

21) that I would never agree to that I think that is so wrong toward the children so (2) so so

22) children must be able to live like all together I so my opinion is that that would be just the

23) worst of all (.) worst of all what could happen that the children would be separate [from

24) each-

Heli's voice became emotional in the course of the utterance, during which silent moment 8 (lines 25 - 30, below) appeared. Especially after Heli's turn, silences emerged (lines 26 and 30) and she seemed to be in her own thoughts or absent:

25) Heli:-other (1) from each other and

26) (4)

27) T2: .hhh yeah

28) Heli: so it is so (.) but that is how I (.) would see that thing that (1) that that (1) all

29) the children would live with me

30) (3)

After silent moment 8, T2 asked how those things would work out in Lasse's mind in the possible event of divorce. Lasse's voice was emotional and while he began his answer. During silent moment 9 (lines 31 - 36, be- 
low), Lasse answered that he could not live without the children around; he was clearly distressed (in line 35), and silence occurred (in line 36). Heli looked at him and the child when Lasse was speaking.

31) Lasse: so that I don't want the day that there would not be [the children (1) living with me

32) that way like there around

33) $T 2$ : [yeah

34) T2: yeah (.) [yes

35) Lasse: [however ((Lasse is on the brink of tears))

36) (4)

After Episode 2, T2 asked a question about the possibility of making a new start as a family. The participants discussed the practical arrangements of this kind of new beginning for the rest of the therapy session. They were no longer as distressed as in Episode 2. The communication between the couple became closer as they spoke, and they looked at each other after Episode 2. In the later sessions, too, the possible divorce was no longer a conversation topic. The couple are still together at the time of writing this paper.

\subsection{Autonomic Nervous System during Silent Moments 6 - 9}

Electrodermal activity during silent moments 6 - 9: Heli's EDA was at a high level before the silent moments. However, her EDA showed frequent decreases during the silent moments, indicating decreased SNS activation. Lasse had many EDA responses during the episode, but the tonic level stayed the same. The therapists had more SNS activation than during Episode 1, especially in the case of T1, who appeared to be more responsive compared to Episode 1. Moreover, during the silent moments in Episode 2, congruent EDA responses appeared between all the participants. An example of EDA activation can be seen in Figure 3. Here, Heli's EDA decreased at the time when Lasse started to pet the child on his lap. This can be seen in the form of a wave-like motion, occurring when he heard that Heli wanted to keep the children (during silent moment 7). The therapists' EDA was responsive, but smoother than that of the clients. The EDA of all the participants rose before silent moment 7, at the point when Heli said that the children would live with her. The EDA of Heli and T2 decreased, whereas that of Lasse and T1 continued to rise at the start of silent moment 7.

Breathing during silent moments 6 - 9: Heli held her breath, and shallow breathing occurred during the silent moments. Lasse was very clearly holding his breath over the silent moments, as if frozen within the moment, despite the fact that having the child on his lap changed his breathing curve slightly irregular. T1's breathing showed no changes during the silent moments, whereas T2 held his breath or took shallow breaths during the silent moments. These breath holdings and shallow breaths suggest that the moments in question were in some way relevant for the participants, especially for Lasse.

Heart rate during Episode 2: Heli's HR was clearly at a lower level than in Episode 1. For Heli and Lasse, the highest HR peaks in Episode 2 occurred during silent moment 9. Their HR responses and levels were similar and simultaneous. T1's HR decreased at the start of Episode 2, after he asked a question about life arrangements in the event of divorce. T2's HR rose before silent moment 9. Congruent HR responses are especially noticeable

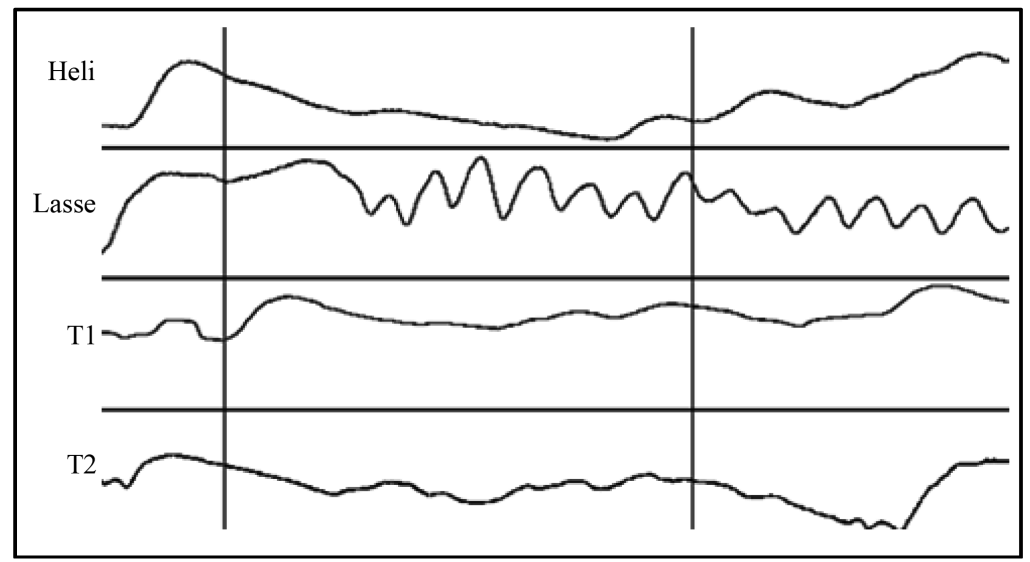

Figure 3. EDA during silent moment 7. The length of the silent moment is 12 seconds. 
between the clients and the therapists, with simultaneous increases and decreases occurring.

\subsection{Episode 2 Stimulated Recall Interviews}

Heli said she had felt tension in her body when she spoke about the possible divorce. Heli noticed that the presence of the child brought positivity and a strong desire to fight for the relationship; this idea was developed in the interview. Lasse explained that he had felt sad during the session, and this sadness occurred again during the interview. Lasse also cried considerably during the interview. T1 reported that he had noticed that the presence of the child changed the atmosphere during the session; as he saw it, the child gave an opportunity for the clients to talk about the possible divorce in a different manner. He had felt calm, even though they talked about very difficult issues. Similarly, T2 felt that the presence of the child brought a more positive atmosphere to the session. T2 explained that he had felt compassion toward Lasse when he noticed how deeply Lasse was moved by the topics discussed.

\section{Discussion and Conclusion}

The first aim of this study was to gain a better understanding of the significance of silent moments in creating words for the not-yet-spoken experiences in couple therapy. The intention was to combine observations from different levels of interaction: therapeutic dialogue, the participants' psychophysiological data (ANS), and the participants' thoughts and feelings during individual SR interviews. The second aim of the study was to see whether synchrony could be found between the participants during the silent moments. In addressing these questions we selected for a mixed methods analysis two episodes containing several silent moments. We focused on the silent moments within conversations about possible divorce and the issue of the children.

This research indicated that speech was merely one way for the clients and therapists to participate in the therapeutic dialogue: during the silent moments the participants were actively involved in the therapeutic conversation-participating through their entire bodies and thoughts, even if they were not talking, or if they seemed externally passive. As expected, the breathing measure turned out to be the most illustrative indicator of the embodied reactions. The analysis showed that the silent moments had important roles when participants were addressing the threat of a divorce: when we examined the progress of the conversation, it became clear that discussion of fundamental issues continued after the silent moments. The analysis also gave evidence of synchrony between the participants, especially in the prosody of speech and in ANS reactions during the silent moments. These moments of synchrony were momentary, lasting only a few seconds.

The silent moments appeared to be relevant for the participants, on the evidence of their ANS reactions and of the content of the conversations. The breathing patterns demonstrated that all the participants reacted by breathing in some particular way during the silent moments. The breathing reactions can be seen most clearly in the case of Lasse, who held his breath during almost every silent moment; moreover, for the therapists, shallow breathing was typical during the silent moments. The holding of breath has been connected to surprise (Feleky, 1916), and shallow breathing is related to high anxiety (Blechert et al., 2006). Such feelings of surprise and anxiety were also reported in the individual SR interviews. Even if breathing occurs in an apparently spontaneous or uncontrolled manner, humans can affect it, at least to some extent, whether consciously or unconsciously. In accordance with the notion of attunement, a person's way of breathing can be sensed by other participants in the interaction situation, and it can influence those others via a communicative message. It is possible that in the session studied, such communicative messages (including holding one's breath and shallow breathing) affected the breathing of all the participants when they became aware of the tension in the atmosphere.

The breathing measure in fact turned out to be a more interesting source of information than we had expected: it gave new information on what happens at the level of bodily reactions during silent moments. The EDA and HR were also informative, but there were many possible artifact reactions; thus, preparing to speak, actually speaking, and bodily movements affected the EDA and the HR. All the ANS measurement sensors were very sensitive to body movement, underlining the extent to which all distractive elements would have to be minimized in further studies.

It is important to note that the ANS measurements alone were not sufficient to describe what happened during the moments of silence. Thus, the SR interviews opened a channel to the participants' inner dialogue; they provided extensive information on the thoughts and feelings that arose during the therapy session, and contained a considerable amount of reflection. This information largely supported our interpretations, making it possible to 
attach meanings to the ANS reactions during the silent moments.

We observed instances of interactional and embodied synchrony between the participants during silent moments. The analysis showed that the participants shared at least some kind of common experience with each other. In several silent moments, the therapists participated in the client's prosody by lowering the pitch of their voices, thus showing empathy toward the clients' expressions. This kind of speech synchrony between the therapist and the client is related to a good therapeutic alliance and hence to the effectiveness of therapy (Ramseyer \& Tschacher, 2011). It is also associated with the client’s experiences of being heard (Seikkula \& Arnkil, 2007). In the present study it was observed that synchrony was fairly brief, lasting only a few seconds, in line with the findings of Altenstein et al. (2013) and Stern (2004). As Seikkula et al. (2015) have observed, it is possible that a given therapist will show more synchronization with only one of the clients during couple therapy. In the present study, we observed that two therapist-client pairs formed, i.e. in Episode 1, when T2 and Heli had a conversation with each other, and T1 remained silent as a "support" to Lasse. In Episode 2, we also found synchrony between the therapists, and between both therapists and Lasse, mostly in the EDA and HR responses.

There are some points that should be taken into account when evaluating the results. Bakhtin (1984) has argued that our mutual dialogue is influenced by (inter alia) life experiences and traumas. In the present study we noticed that Heli's embodied reactions were often the largest among all the participants. It is possible that the experience of intimate partner violence could have intensified her reactions, and also that the physiological changes related to post-pregnancy could have had an effect. Moreover, Lasse's medication for depression could have diminished both his emotional and his embodied reactions during the measurement session. It is also possible that having the child on his lap during Episode 2 might have calmed Lasse's embodied reactions, and had a further calming effect on the other participants. These aspects point to the need for further studies, and to certain points that need to be taken into account regarding ANS measurements.

As a conclusion, we suggest that the silent moments were important in the therapeutic conversations, helping to create a rhythm and to allow the conversation to continue, and giving the participants a chance to react and think. This can be seen as necessary when there is discussion of fundamental issues such as the permanence of the relationship, and the possibility that family members will be separated from each other. Interestingly, even though they both showed bodily arousal, the clients did not start to quarrel, and this is a feature that could be attributed to the calmness of the conversational rhythm. Along similar lines, MacGregor, Corley and Donaldson (2010) found that the listener hears what is said better, and takes better account of what is said, when soft prosody is employed. Heli expressed many meaningful issues with soft prosody. Afterwards, during the SR interviews, she mentioned that she hoped that Lasse had-for the first time-truly heard what she was saying. Lasse's breathing indicated that he at least reacted to what he heard. We suggest that the calm rhythm of the conversation contributed to the participants' ability to hear what was said and to take matters better into account; thus, it advanced the productive elements of the conversation and helped the couple to arrive at words for the not-yetspoken conceptions.

On the basis of the analyses and the overall information on this therapy case, it can be surmised that the silent moments in this particular session had some role in changing the couple's situation. The participants were able to address the threat of a divorce through their outer, inner, and embodied dialogue, and they managed to create together words and understandings that could move them towards a resolution of the situation. However, we cannot say at this point that definite conclusions for clinical practice emerge. There is a need for further studies, more cases, and more ways to analyze this kind of mixed method data if we are to arrive at reliable conclusions on the significance of silent moments in therapy interaction.

\section{Acknowledgements}

Authors want to thank Lauri Viljanto and Petri Kinnunen for their assistance with autonomic nervous system measurements. This research has been funded by the Academy of Finland (Human Mind Program, grant number 265492).

\section{References}

Altenstein, D., Krieger, T., \& Grosse Holtforth, M. (2013). Interpersonal Microprocesses Predict Cognitive-Emotional Processing and the Therapeutic Alliance in Psychotherapy for Depression. Journal of Counseling Psychology, 60, 445-452. http://dx.doi.org/10.1037/a0032800 
Bakhtin, M. (1984). Problems of Dostojevskij's Poetics: Theory and History of Literature (Vol. 8). Manchester, England: Manchester University Press.

Barth-Weingarten, D., Reber, E., \& Selting, M. (2010). Prosody in Interaction. Amsterdam: John Benjamins Publishing. http://dx.doi.org/10.1075/sidag.23

Birdwhistell, R. L. (1952). Introduction to Kinesics: An Annotation System for Analysis of Body Motion and Gesture. Washington, DC: Department of State, Foreign Service Institute.

Blechert, J., Lajtman, M., Michael, T., Margraf, J., \& Wilhelm, F. H. (2006). Identifying Anxiety States Using Broad Sampling and Advanced Processing of Peripheral Physiological Information. Biomedical Sciences Instrumentation, 42, 136141.

Bràten, S., \& Trevarthen, C. (2007). From Infant Intersubjectivity and Participant. On Being Moved: From Mirror Neurons to Empathy, 68, 21.

Cook, J. J. (1964). Silence in Psychotherapy. Journal of Counseling Psychology, 11, 42. http://dx.doi.org/10.1037/h0049176

Couper-Kuhlen, E., \& Selting, M. (1996). Towards an Interactional Perspective on Prosody and a Prosodic Perspective on Interaction. In E. Couper-Kuhlen, \& M. Selting (Eds.), Prosody in Conversation. Interactional Studies (pp. 11-57). Cambridge: Cambridge University Press.

Cromby, J. (2012). Feeling the Way: Qualitative Clinical Research and the Affective Turn. Qualitative Research in Psychology, 9, 88-98. http://dx.doi.org/10.1080/14780887.2012.630831

Feleky, A. (1916). The Influence of the Emotions on Respiration. Journal of Experimental Psychology, 1, $218-241$. http://dx.doi.org/10.1037/h0073754

Gee, J. P. (1986). Units in the Production of Narrative Discourse. Discourse Processes, 9, 391-422. http://dx.doi.org/10.1080/01638538609544650

Gendlin, E. T. (1996). Focusing-Oriented Psychotherapy: A Manual of the Experiential Method. New York: Guilford Press.

Hill, C. E., Thompson, B. J., \& Ladany, N. (2003). Therapist Use of Silence in Therapy: A Survey. Journal of Clinical Psychology, 59, 513-524. http://dx.doi.org/10.1002/jclp.10155

Hrdy, S. (2009). Mothers and Others: The Evolutionary Origins of Mutual Understanding. Cambridge, MA: Belknap Press.

Kagan, N., Krathwohl, D. R., \& Miller, R. (1963). Stimulated Recall in Therapy Using Video Tape: A Case Study. Journal of Counseling Psychology, 10, 237-243. http://dx.doi.org/10.1037/h0045497

Kinnunen, M., Rusko, H., Feldt, T., Kinnunen, U., Juuti, T., Myllymäki, T., et al. (2006). Stress and Relaxation Based on Heart Rate Variability: Associations with Self-Reported Mental Strain and Differences between Waking Hours and Sleep. In Promotion of Well-Being in Modern Society (pp. 136-139).

Kircher, T. T., Brammer, M. J., Levelt, W., Bartels, M., \& McGuire, P. K. (2004). Pausing for Thought: Engagement of Left Temporal Cortex during Pauses in Speech. Neuroimage, 21, 84-90. http://dx.doi.org/10.1016/j.neuroimage.2003.09.041

Kreibig, S. D. (2010). Autonomic Nervous System Activity in Emotion: A Review. BiologicalPsychology, 84, $394-421$. http://dx.doi.org/10.1016/j.biopsycho.2010.03.010

Kykyri, V.-L., Karvonen, A., Wahlström, J., Kaartinen, J., Penttonen, M., \& Seikkula, J. (2015). Soft Prosody and Embodied Attunement in Therapeutic Interaction: A Mixed Method Case Study of a Moment of Change. (under review)

Lane, R. C., Koetting, M. G., \& Bishop, J. (2002). Silence as Communication in Psychodynamic Psychotherapy. Clinical Psychology Review, 22, 1091-1104. http://dx.doi.org/10.1016/S0272-7358(02)00144-7

Lapides, F. (2011). The Implicit Realm in Couples Therapy: Improving Right Hemisphere Affect-Regulating Capabilities. Clinical Social Work Journal, 39, 161-169. http://dx.doi.org/10.1007/s10615-010-0278-1

Levenson, R. W. (2014). The Autonomic Nervous System and Emotion. Emotion Review, 6, 100-112. http://dx.doi.org/10.1177/1754073913512003

Levenson, R. W., \& Ruef, A. M. (1997). Physiological Aspects of Emotional Knowledge and Rapport. In Empathic Accuracy (pp. 44-72). New York: Guilford Press.

Levitt, H. M. (2001). Clients’ Experiences of Obstructive Silence: Integrating Conscious Reports and Analytic Theories. Journal of Contemporary Psychotherapy, 31, 221-244. http://dx.doi.org/10.1023/A:1015307311143

MacGregor, L. J., Corley, M., \& Donaldson, D. I. (2010). Listening to the Sound of Silence: Disfluent Silent Pauses in Speech Have Consequences for Listeners. Neuropsychologia, 48, 3982-3992.

http://dx.doi.org/10.1016/j.neuropsychologia.2010.09.024

Marci, C. D., \& Orr, S. P. (2006). The Effect of Emotional Distance on Psychophysiologic Concordance and Perceived Empathy between Patient and Interviewer. Applied Psychophysiology and Biofeedback, 31, 115-128. http://dx.doi.org/10.1007/s10484-006-9008-4 
Marci, C. D., Ham, J., Moran, E., \& Orr, S. P. (2007). Physiologic Correlates of Perceived Therapist Empathy and SocialEmotional Process during Psychotherapy. The Journal of Nervous and Mental Disease, 195, 103-111. http://dx.doi.org/10.1097/01.nmd.0000253731.71025.fc

Messina, I., Palmieri, A., Sambin, M., Kleinbub, J. R., Voci, A., \& Calvo, V. (2013). Somatic Underpinnings of Perceived Empathy: The Importance of Psychotherapy Training. Psychotherapy Research, 23, 169-177. http://dx.doi.org/10.1080/10503307.2012.748940

Peräkylä, A., \& Sorjonen, M. (2012). Emotion in Interaction. Oxford: Oxford University Press.

Potter, J., \& Edwards, D. (2001). Discursive Social Psychology. The New Handbook of Language and Social Psychology, 9, 103-118.

Quillman, T. (2012). Neuroscience and Therapist Self-Disclosure: Deepening Right Brain to Right Brain Communication between Therapist and Patient. Clinical Social Work Journal, 40, 1-9. http://dx.doi.org/10.1007/s10615-011-0315-8

Ramseyer, F., \& Tschacher, W. (2011). Nonverbal Synchrony in Psychotherapy: Coordinated Body Movement Reflects Relationship Quality and Outcome. Journal of Consulting and Clinical Psychology, 79, 284-295.

http://dx.doi.org/10.1037/a0023419

Reed, B. S. (2010). Analysing Conversation: An Introduction to Prosody. Palgrave Macmillan.

Sabbadini, A. (1991). Listening to Silence. British Journal of Psychotherapy, 7, 406-415. http://dx.doi.org/10.1111/j.1752-0118.1991.tb01145.x

Seikkula, J., \& Arnkil, T. E. (2007). Dialogical Meetings in Social Networks. London: KarnacBooks.

Seikkula, J., Karvonen, A., Kykyri, V.-L., Kaartinen, J., \& Penttonen, M. (2015). The Embodied Attunement of Therapists and a Couple within Dialogical Psychotherapy: An Introduction to the Relational Mind Research Project. Family Process. http://dx.doi.org/10.1111/famp.12152

Sheets-Johnstone, M. (2010). Kinesthetic Experience: Understanding Movement Inside and Out. Body, Movement and Dance in Psychotherapy, 5, 111-127. http://dx.doi.org/10.1080/17432979.2010.496221

Slovák, P., Tennent, P., Reeves, S., \& Fitzpatrick, G. (2014). Exploring Skin Conductance Synchronisation in Everyday Interactions. Submitted to CHI' 14. http://dx.doi.org/10.1145/2639189.2639206

Stern, D. N. (2004). The Present Moment: In Psychotherapy and Everyday Life. New York: W. W. Norton \& Co. http://search.proquest.com/docview/620286146?accountid=11774

Trevarthen, C. (2001). Intrinsic Motives for Companionship in Understanding: Their Origin, Development, and Significance for Infant Mental Health. Infant Mental Health Journal, 22, 95-131. http://dx.doi.org/10.1002/1097-0355(200101/04)22:1<95::AID-IMHJ4>3.0.CO;2-6

Weiste, E., \& Peräkylä, A. (2014). Prosody and Empathic Communication in Psychotherapy Interaction. Psychotherapy Research, 24, 687-701. http://dx.doi.org/10.1080/10503307.2013.879619

Wepfer, R. (1996). Silence in Psychotherapy: A Quantitative Analysis. 27th Annual Meeting of the Society for Psychotherapy Research, Amelia Island, Florida.

\section{Appendix 1: Transcript Notation}

Symbol

and (1) then

and (.) then

((smiling))

Underlining

[and well

and it feels bad

.hhh

$\uparrow$ anymore
Meaning

The number in rounded brackets represents pauses in seconds.

A period in rounded brackets indicates "micro-pauses" of less than 0.2 seconds.

Double rounded brackets contain relevant contextual information added by the transcribers.

Underlining indicates emphasis.

Overlapping utterances are marked by single square brackets.

The degree sign indicates a significantly lower volume than in the surrounding speech.

This indicates inhalation between words.

Upward-pointing arrows indicate rising intonation. 